\title{
ESTUDIO MORFOLÓGICO DE HELECHOS FÉRTILES HALLADOS EN LA FORMACIÓN BAQUERÓ (CRETÁCICO INFERIOR), PROVINCIA DE SANTA CRUZ, ARGENTINA
}

\author{
Liliana VILLAR DE SEOANE \\ CONICET. División Paleobotánica, Museo Argentino de Ciencias Naturales \\ "B. Rivadavia", Av. A. Gallardo 470, (1405), Buenos Aires, Argentina.
}

\begin{abstract}
Villar de Seoane, L. 1996. Estudio morfológico de helechos fértiles hallados en la Formación Baqueró (Cretácico Inferior), Provincia de Santa Cruz, Argentina. [Morphological study of fertile ferns from the Baqueró Formation (Lower Cretaceous), Santa Cruz Province, Argentina]. Revista Española de Paleontología, 11 (1), 83-90. ISSN 0213-6937.
\end{abstract}

\begin{abstract}
Frond remains are studied from the Baqueró Formation in Santa Cruz Province, Patagonia, Argentina. The leaf compressions and spores of two ferns, Cladophlebis cyathifolia n. sp. and Cladophlebis tripinnata Archangelsky are described using light and electron microscopy (SEM). The morphological differences between these two ferns are pointed out.
\end{abstract}

Keywords: Ferns, fronds, compressions, spores, Baqueró Formation, Santa Cruz Province, Argentina, Cretaceous.

\section{RESUMEN}

En la Formación Baqueró, Provincia de Santa Cruz, Argentina, fueron halladas compresiones de frondes de helechos fósiles con esporangios en conexión orgánica, conteniendo esporas en su interior. Se describen aquí dos especies, Cladophlebis cyathifolia n. sp. y Cladophlebis tripinnata Archangelsky utilizando microscopía óptica y electrónica de barrido (MEB), reconociendo diferencias morfológicas entre ambas.

Palabras clave: Helechos, frondes, compresiones, esporas, Formación Baqueró, Provincia de Santa Cruz, Argentina, Cretácico.

\section{INTRODUCCIÓN}

En el presente trabajo se realiza el estudio morfológico de pinnas fértiles y estériles de Filicales, halladas en la Formación Baqueró (Cretácico Inferior) de la provincia de Santa Cruz (Archangelsky, 1963 a).

La Formación Baqueró aflora sin interrupciones en el piso de una amplia depresión ubicada al sur del río Deseado, en un área comprendida entre los paralelos $47^{\circ}$. $49^{\circ}$ y los meridianos $68^{\circ}-69^{\circ} 30^{\prime}$, en la provincia de Santa Cruz (Fig. 1). En toda esta área se destacan pequeñas elevaciones discontinuas de rocas piroclásticas de tonalidades rosadas a rojizas, duras, y a menudo fuertemente inclinadas, sobre las cuales se apoyan los sedimentos fosilíferos de esta formación. La edad de la misma fue establecida sobre la base de estudios paleobotánicos y palinológicos (Archangelsky y Gamerro 1966 a y b), en el período Cretácico Inferior (Barremiense tardío - Aptiense temprano), con una antigüedad aproximada de 120 millones de años (Archangelsky, 1967).
Las Filicales estudiadas corresponden a dos familias diferentes: Cyatheaceae y Dennstaedtiaceae.

La especie Cladophlebis tripinnata Archangelsky, atribuible a la familia Dennstaedtiaceae fue hallada en la localidad Estancia Bajo Tigre de la Formación Baqueró y está representada por dieciocho ejemplares que contienen pinnas fértiles y estériles, de posición basal, media y apical. La especie creada por Archangelsky y descrita para la misma Formación (1963 b), poseía frondes estériles tripinnadas asociadas a esporangios aislados que no contenían esporas. El nuevo material estudiado posee esporangios en conexión orgánica con esporas en su interior, hecho que permitió aproximar su clasificación, por comparación de su arquitectura foliar y sus esporas con especies actuales.

Las frondes atribuibles a la familia Cyatheaceae fueron descritas como Cladophlebis cyathifolia y corresponden a una nueva especie. Las mismas fueron halladas en la localidad Estancia Bajo Grande de la Formación Baqueró y están representadas por cinco ejemplares, también con pinnas fértiles y estériles. Se 


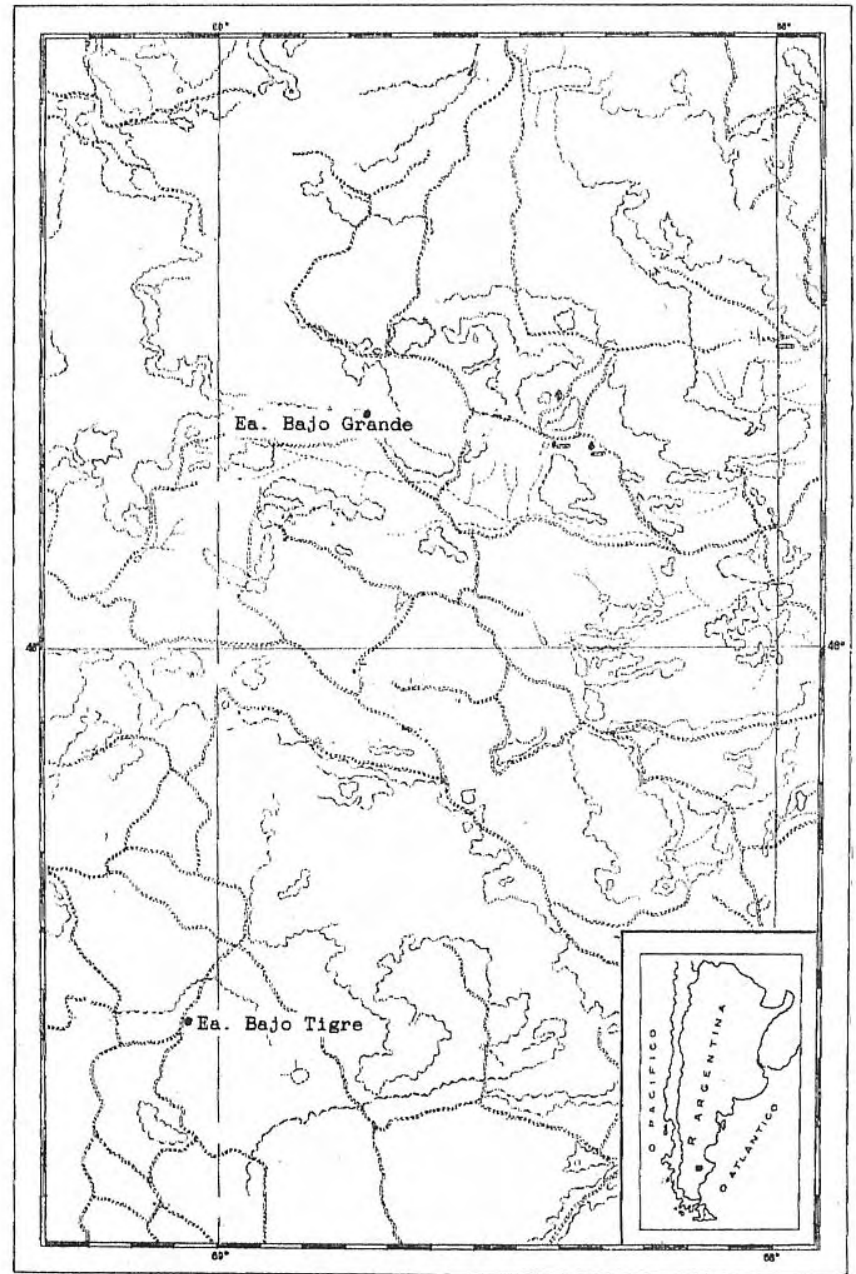

Figura 1. Ubicación geográfica de las localidades fosilíferas Estancia Bajo Tigre y Estancia Bajo Grande de la Formación Baqueró. (Archangelsky, 1967, modificado).

trata de un helecho posiblemente arborescente, con frondes por lo menos bipinnadas, asociadas a esporangios en conexión orgánica llevando esporas en su interior, hecho que posibilitó su atribución sistemática a esta familia, por comparación con especies actuales.

Las esporas asociadas a estas frondes (Cyathidites minor y Cyathidites sp. A) son muy frecuentes en estado disperso en distintos niveles fosilíferos de la Formación Baqueró. Tres especies diferentes de Cyatheaceae y dos de Dennstaedtiaceae fueron recientemente descritas (Archangelsky y Villar de Seoane, 1994). Dos de ellas, Cyathidites australis y Cyathidites minor, son muy abundantes en las asociaciones polínicas, hecho que sugeriría su importancia como componente de las
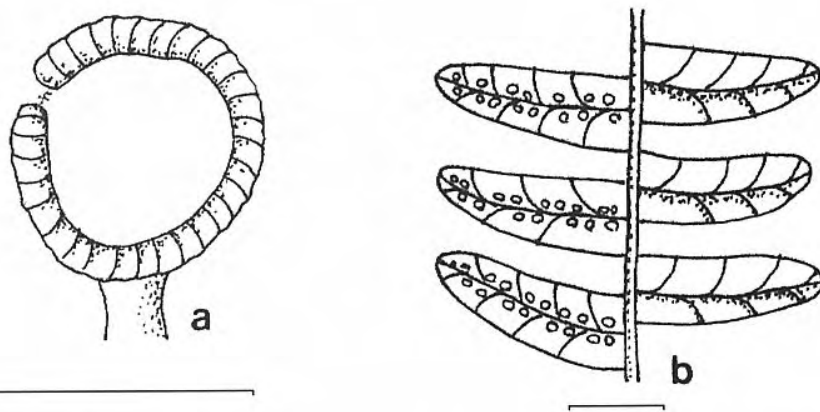

Figura 2. Cladophlebis cyathifolia n. sp. a: Esporangio de anillo completo; b: Pínnulas fértiles mostrando la posición de los esporangios y el tipo de venación. Reglillas: $\mathrm{a}=100 \mu \mathrm{m} ; \mathrm{b}=0,5 \mathrm{~cm}$.

comunidades vegetales que habitaron esa área durante el Cretácico Inferior.

\section{MATERIALES, MÉTODOS Y REPOSITORIO}

Las Pteridófitas poseen una epidermis muy delicada que generalmente se pierde con el transcurso del tiempo geológico, quedando de sus frondes solamente las improntas; sin embargo, los ejemplares aquí analizados, poseen pínnulas con abundantes restos cuticulares y esporangios asociados, hecho que permitió realizar un estudio detallado de los mismos y obtener esporas del interior de los esporangios, brindando un importante aporte taxonómico que facilitó su clasificación.

Las compresiones estudiadas, se hallan incluidas en tobas fosilíferas identificadas con la sigla $\mathrm{BA} \mathrm{Pb}$; de ellas se extrajeron pequeñas porciones que fueron montadas en tacos de bronce y adheridas a los mismos con esmalte incoloro (sigla BA Pb MEB). El material así fijado fue observado con un microscopio electrónico de barrido JEOL T-100 del Servicio de Microscopía Electrónica de la Facultad de Ciencias Naturales de la Universidad de La Plata. Para las fotografías se utilizó una película AGFA APX 100.

Las esporas fueron extraídas directamente de esporangios que aún se conservan en la superficie de las compresiones, o de pequeños fragmentos pinnulares que fueron tratados con los métodos químicos convencionales. El material recuperado fue montado en glicerina-gelatina (sigla $\mathrm{BA} \mathrm{Pb} \mathrm{Pm)} \mathrm{y} \mathrm{fotografiado} \mathrm{con} \mathrm{un} \mathrm{microscopio}$ Dialux, utilizando una película Kodak T MAX 100.

Para la descripción de la arquitectura foliar, se utilizó la clasificación de Hickey (1974).

Todo el material estudiado se halla depositado en la

\section{Lámina I}

\section{Cladophlebis cyathifolia $\mathrm{n} . \mathrm{sp}$.}

1 Aspecto general del holotipo. BA Pb 11479. Reglilla $=$ $0,5 \mathrm{~cm}$.

2 Detalle de las pínnulas. BA Pb 11479. Reglilla $=0,5 \mathrm{~cm}$.
3 Grupo de esporas asociadas a un esporangio x 1250. BA $\mathrm{Pb}$ Pm 5135.

4 Cara proximal de una espora x 1250. BA Pb Pm 5136.

5 Detalle de la vena media de una pínnula x 200. BA Pb MEB 60. 
Lámina I
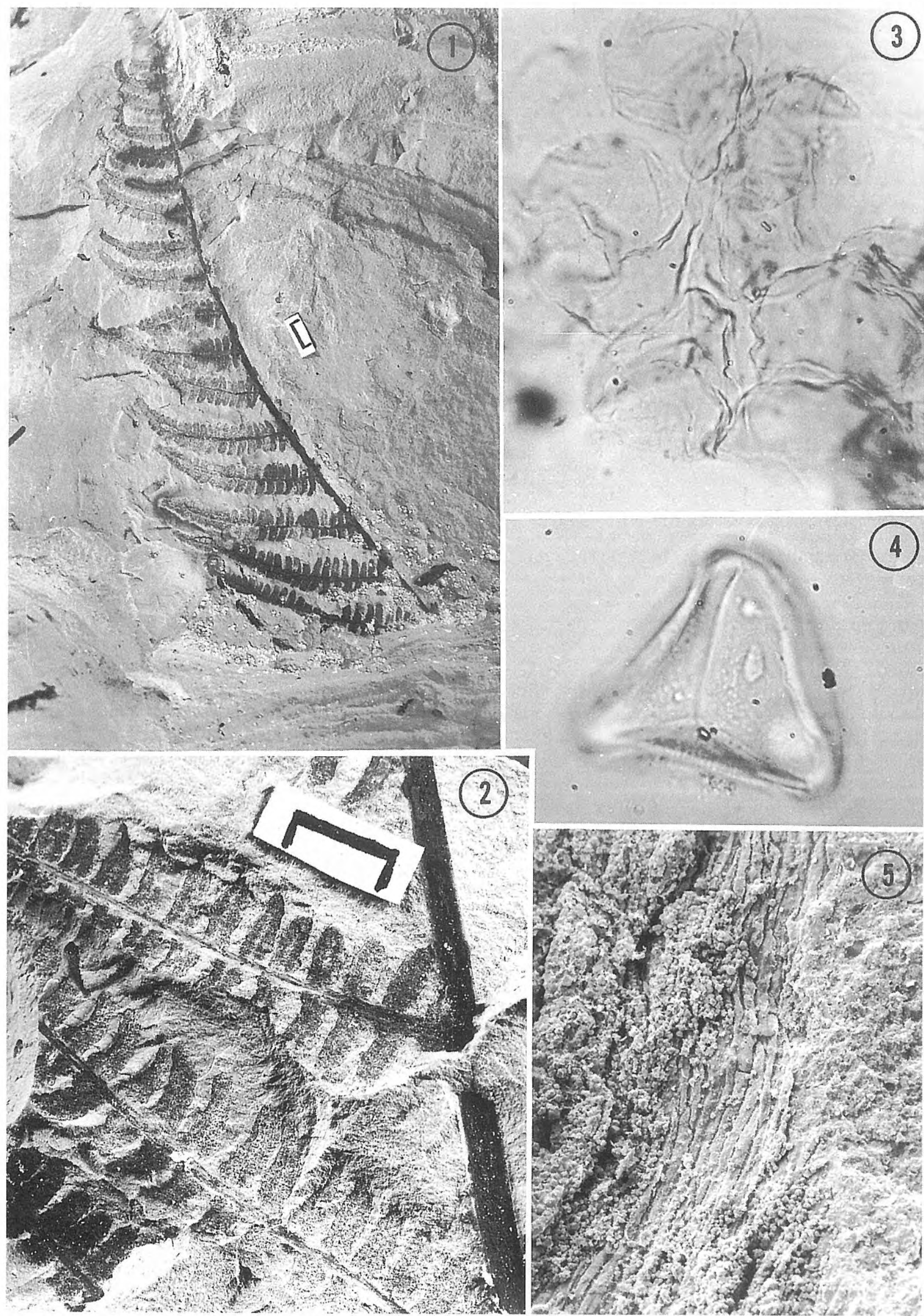

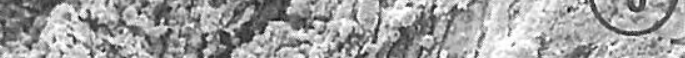

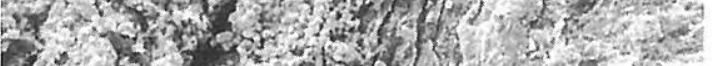

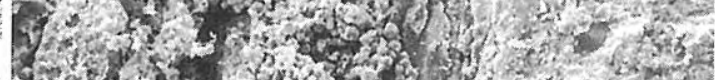
20.5

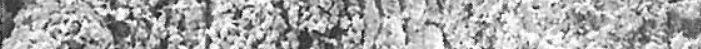
1.8.

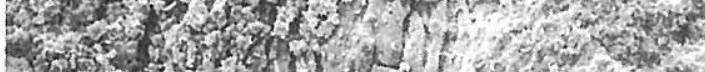

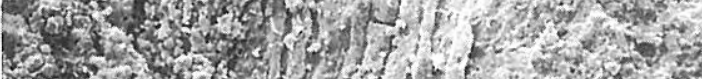

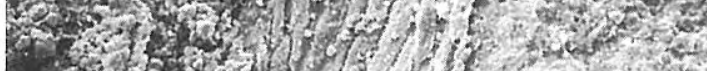

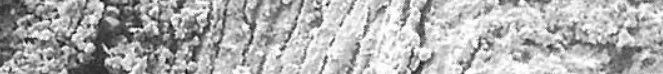

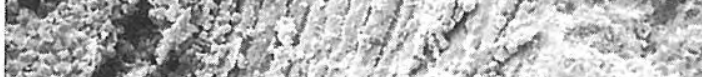

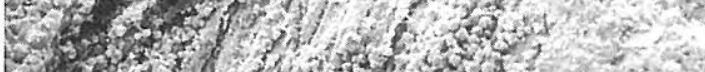

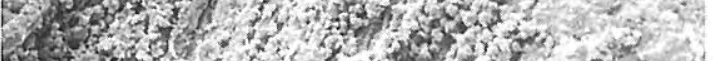

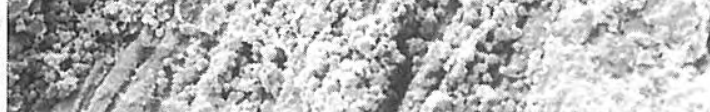

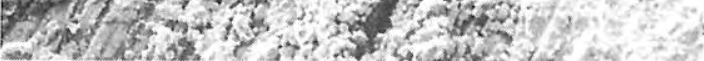

Revista Española de Paleontología, 11(1), 1996. 
Colección Paleobotánica del Museo Argentino de Ciencias Naturales "Bernardino Rivadavia".

\section{DESCRIPCIONES SISTEMÁTICAS}

\author{
ORDEN FILICALES Engler y Prantl, 1902 \\ Familia CYATHEACEAE Kaulfuss, 1827 \\ Género Cladophlebis Brongniart 1849
}

Especie tipo: Cladophlebis albertsii (Dunker) Brongniart 1849.

\section{Cladophlebis cyathifolia $\mathrm{n}$. sp. Lám. I, figs. 1-5; Fig. 2}

Derivatio nominis: El epíteto específico alude a la familia Cyatheaceae por la forma de sus frondes.

Holotipo: BA Pb 11479; BA Pb Pm 5135, coord.: 34 / 95; y BA Pb MEB 60.

\section{Paratipo: $\mathrm{BA} \mathrm{Pb} 11415$.}

Otro material estudiado: $\mathrm{BA} \mathrm{Pb} 11425,11416$ y 11419 ; BA Pb Pm 5136.

Localidad tipo: Estancia Bajo Grande.

\section{Diagnosis}

Helecho leptosporangiado, con pínnulas fértiles y vegetativas. Frondes por lo menos bipinnadas. Pínnulas opuestas, simétricas, oblongo-angostas, ápice redondeado, base truncada completamente insertada en el raquis y márgenes enteros. Vena media bien definida y venas secundarias simples. Esporangios aislados de anillo completo. Esporas trilete de exina lisa a micropunteada.

Leptosporangiate fern with fertile and vegetative pinnules. Bipinnate fronds. Opposite, symmetrical, oblong-narrow pinnules, with rounded apex, a wide base entirely fused with the rachis, and entire margins. Straight central vein and simple secondary veins. Isolated sporangia with complete annulus. Trilete spores with smooth or micropunctate exine.

\section{Descripción}

Fragmento de fronde de un helecho posiblemente arborescente, leptosporangiado, con pínnulas fértiles y estériles. Frondes bipinnadas. Pinna de primer orden de 16 $\mathrm{cm}$ de largo aproximadamente, raquis de $0,1 \mathrm{~cm}$ de ancho, angostándose hacia el ápice.

Pinnas de segundo orden sub-alternas, con un ángulo de inserción de $45^{\circ}$ con relación al raquis primario. Las pinnas de la base presentan un largo de $4 \mathrm{~cm}$ y un ancho de $0,7 \mathrm{~cm}$, con un raquis de $0,5 \mathrm{~mm}$ de ancho. Hacia el ápice, las pinnas reducen su tamaño hasta alcanzar un largo de $0,5 \mathrm{~cm}$ y un ancho de $0,2 \mathrm{~cm}$, finalizando en una única pinna vertical y paralela al raquis primario de $1 \mathrm{~cm}$ de largo y $0,3 \mathrm{~cm}$ de ancho.

Pínnulas opuestas, simétricas, oblongo-angostas, de ápice redondeado, base truncada completamente insertada en el raquis y márgenes enteros. Presentan una orientación perpendicular al raquis.

Las pínnulas de la base miden $0,4 \mathrm{~cm}$ de largo y $0,1 \mathrm{~cm}$ de ancho, disminuyendo estas dimensiones hacia el ápice, terminando en una única pínnula de $0,4 \mathrm{~cm}$ de largo por 0,1 $\mathrm{cm}$ de ancho, de posición vertical y paralela al raquis de la pinna secundaria.

Venación camptódroma, vena media bien definida, derecha y ramificada, orientada perpendicularmente al raquis. Venas secundarias simples, derechas y $\sin$ ramificaciones.

La observación con MEB de los restos cuticulares muestra la presencia de orificios alargados, irregularmente distribuidos, que indicarían la posición de los estomas.

Esporangios aislados, ovales a redondeados, de 0,1 - 0,2 mm de diámetro aproximadamente, con anillo completo. Los esporangios se hallan ubicados en la cara abaxial de la pínnula, a ambos lados de la vena media.

Esporas trilete de contorno ecuatorial triangular a subtriangular de $42 \mu \mathrm{m}$ de diámetro, con lados cóncavos a rectos y ángulos redondeados. Lesura de ramas rectas y angostas, que se extienden hasta el borde ecuatorial, alcanzando una longitud de $28 \mu \mathrm{m}$. Exina delgada de $1 \mu \mathrm{m}$ de espesor. Cara proximal levemente piramidal, lisa a microperforada. Cara distal convexa, ornamentada por fósulas isodiamétricas a alargadas e irregulares de $0,5 \mu \mathrm{m}$ de ancho y $3 \mu \mathrm{m}$ de largo. Estas esporas pertenecen a la especie Cyathidites minor Couper y son semejantes a las encontradas en la Formación Baqueró, Anfiteatro de Ticó, Nivel Fosilífero Williamsonia y Nivel Fosilífero Basal; y en Estancia Bajo Tigre, Nivel Fosilífero Brachyphyllum (Archangelsky y Villar de Seoane, 1994, pág. 42).

En el sedimento correspondiente a la fronde descrita, luego del tratamiento químico convencional, se encontró una asociación polínica con abundantes granos de polen bisacados. Las escasas esporas halladas corresponden a briófitas y pteridófitas, siendo estas últimas mayorita-riamente del género Cyathidites, con exina lisa a microperforada.

\section{Lámina II}

Cladophlebis tripinnata (Archangelsky) emend.

1 Aspecto general de un ejemplar. BA Pb 4604. Reglilla $=0,5 \mathrm{~cm}$.

2 Grupo de esporas asociadas a un esporangio x 1250 . BA Pb Pm 5137.
3 Cara proximal de una espora x 1250. BA Pb Pm 5138.

4 Detalle de las pínnulas. BA Pb 4604. Reglilla $=0,5 \mathrm{~cm}$.

5 Detalle de la vena media y venas secundarias de una pínnula x 35. BA Pb MEB 59. 
Lámina II
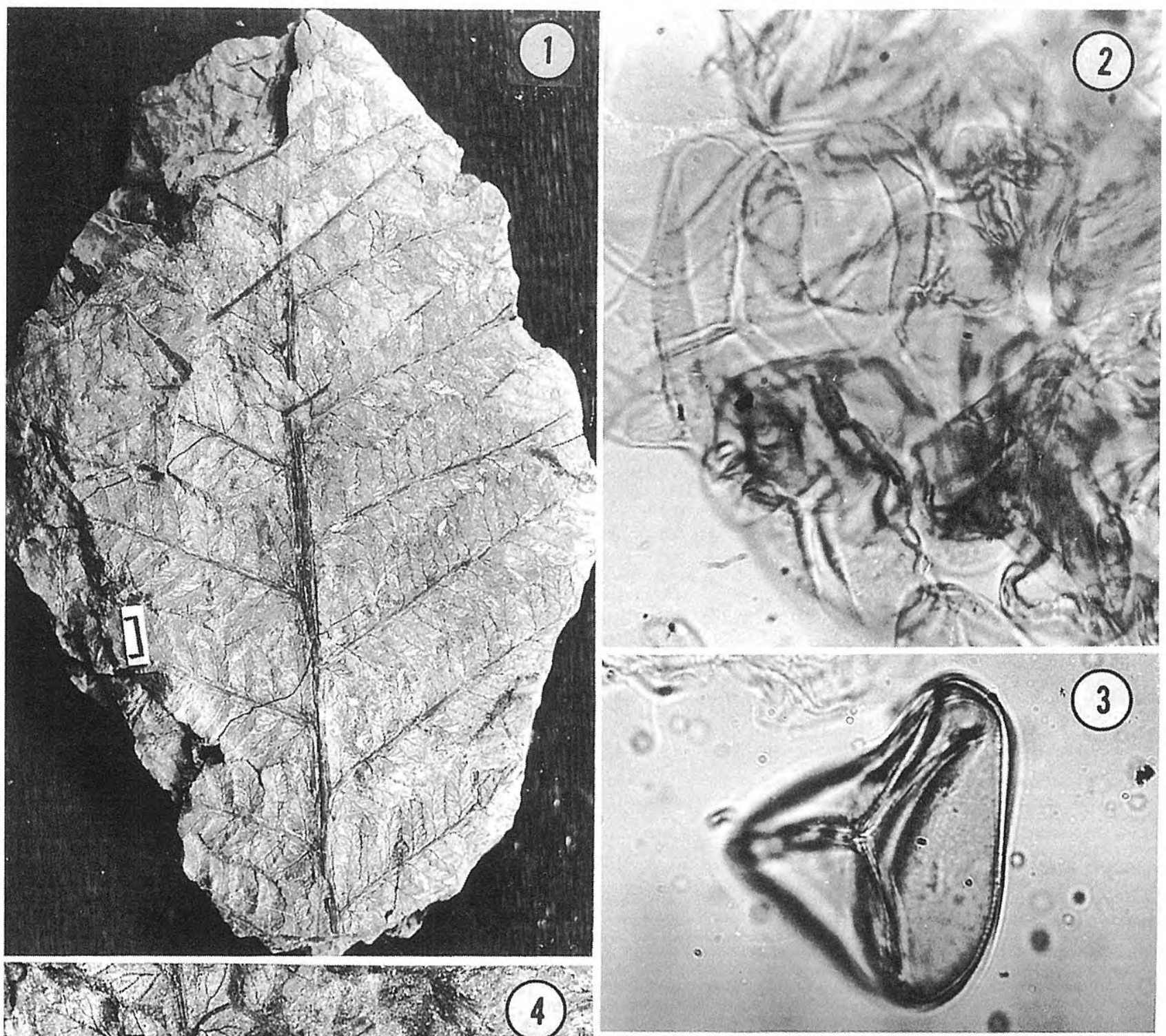

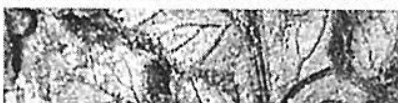

(1)

(4)

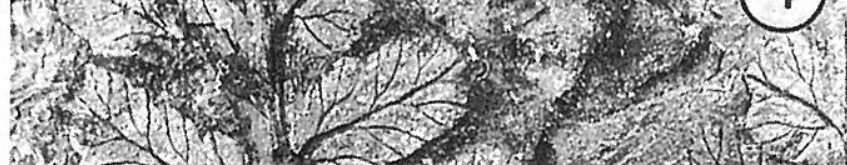

M
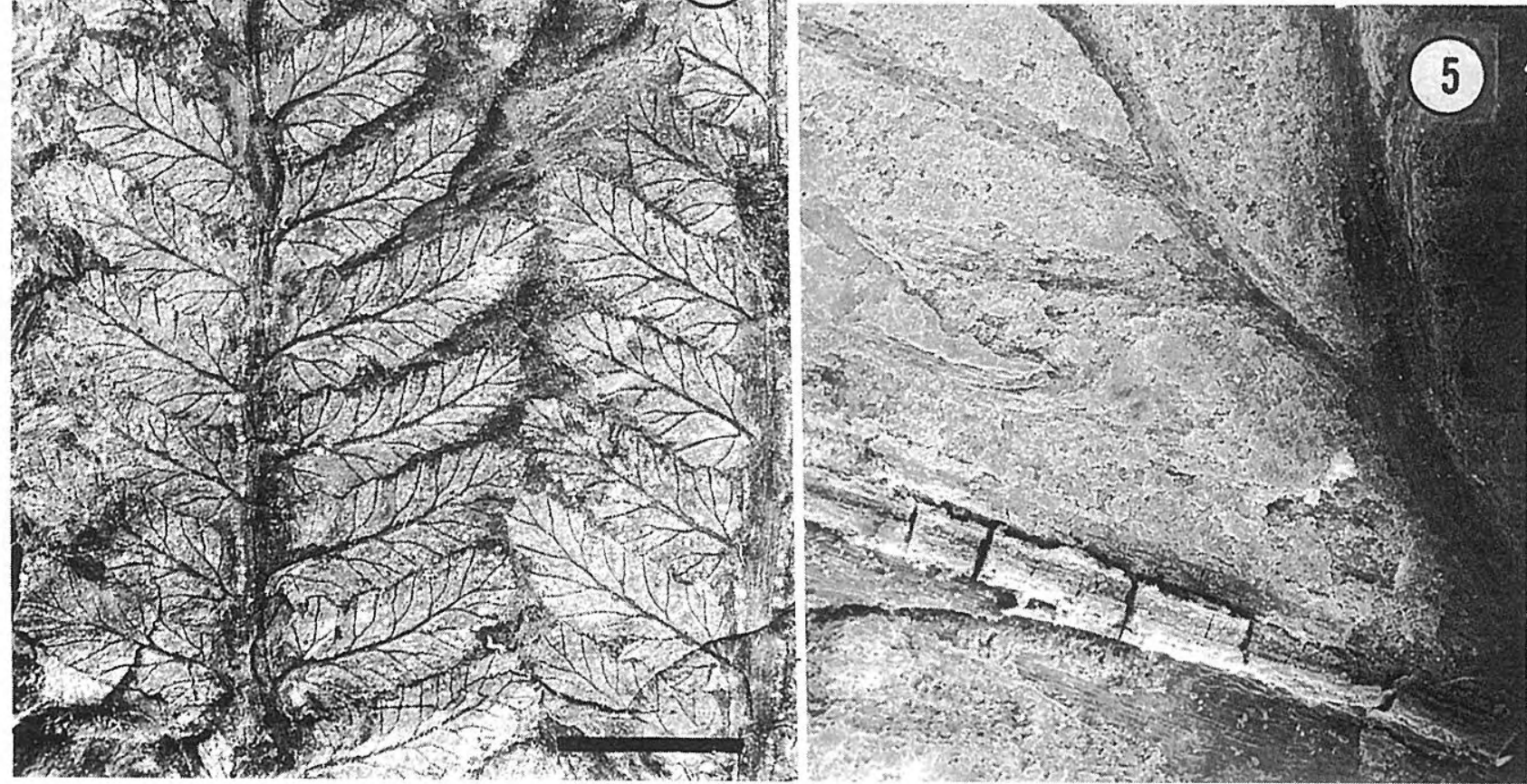

Revista Española de Paleontología, 11(1), 1996. 

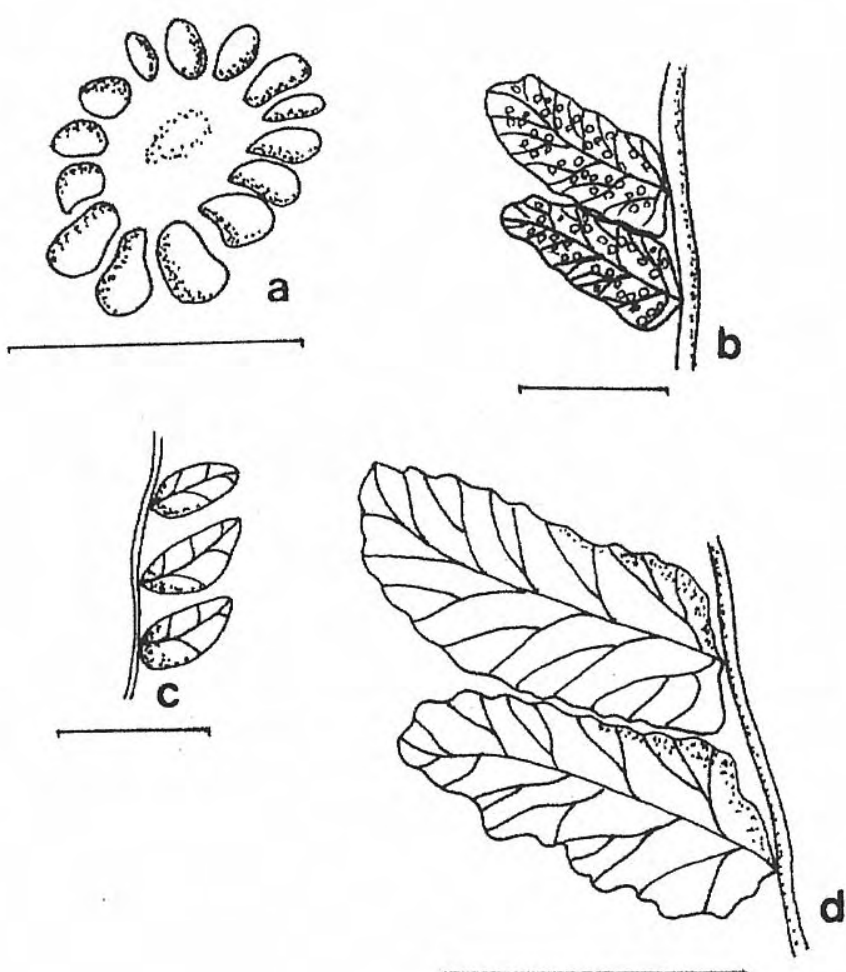

Figura 3. Cladophlebis tripinnata (Archang.) emend. a: Base de un esporangio; b: Pínnulas fértiles mostrando la posición de los esporangios y el tipo de venación; c: Pínnulas apicales; d: Pínnulas basales. Reglillas: $\mathrm{a}=100 \mu \mathrm{m} ; \mathrm{b}, \mathrm{c}$ y d $=0,5 \mathrm{~cm}$.

\section{Comparaciones}

Cladophlebis cyathifolia n. sp. se diferencia de Cladophlebis tripinnata Archangelsky por poseer pínnulas de menor tamaño con márgenes enteros y venas secundarias simples.

\section{Procedencia}

Formación Baqueró, Provincia de Santa Cruz, Argentina.

\section{Edad}

Cretácico Inferior (Barremiense tardío - Aptiense temprano).

\section{Familia DENNSTAEDTIACEAE Pichi-Sermolli}

\section{Cladophlebis tripinnata (Archangelsky) emend. Lám. II, figs. 1-5; Fig. 3}

\footnotetext{
* 1963 Cladophlebis tripinnata Archangelsky, 59-62, lám. 1 , figs. $1-4$.
}

Material estudiado: BA Pb 4604, 4605, 4606, 4607, 4608, 4609, 4610, 4611, 11571, 11572, 11573, 11574, 11575, $11576,11577,11578,11579$ y $11580 ; \mathrm{BA} \mathrm{Pb} \mathrm{Pm} 5137$ y 5138; BA Pb MEB 59.

\section{Diagnosis enmendada}

Helecho leptosporangiado, con pínnulas fértiles y vegetativas. Fronde tripinnada. Pínnulas alternas, simétricas, lanceoladas, de ápice redondeado, base decurrente y márgenes crenados a lobulados, con un ángulo de inserción de $60^{\circ}$. Vena media derecha y ramificada. Venas secundarias recurvadas y ramificadas, con un ángulo de divergencia agudo. Esporangios aislados. Esporas trilete y monolete de exina lisa a micropunteada.

Leptosporangiate fern with fertile and vegetative pinnules. Tripinnate fronds. Alternate, symmetrical, lanceolate pinnules, with rounded apex, a decurrent base and crenated to lobulate margins, with an insertion angle of $60^{\circ}$. Straight and branched central vein. Recurvate and branched secondary veins with a narrow angle of divergence. Isolated sporangia. Trilete and monolete spores with smooth or micropunctate exine.

\section{Descripción}

Helecho leptosporangiado, con pínnulas fértiles y estériles. Fronde bipinnada, pudiendo ser tripinnada.

Raquis primario de $0,3 \mathrm{~cm}$ de ancho, con quilla longitudinal media. Pinna de primer orden fragmentada e incompleta, de más de $12 \mathrm{~cm}$ de ancho. Raquis secundario de $0,1 \mathrm{~cm}$ de ancho, decurrente, con quilla media y ángulo de inserción de $60^{\circ}$.

Pinnas de segundo orden alternas, midiendo las basales 6 $\mathrm{cm}$ de largo y $2 \mathrm{~cm}$ de ancho y las apicales $3,6 \mathrm{~cm}$ de largo y $0,8 \mathrm{~cm}$ de ancho.

Pínnulas alternas, simétricas, lanceoladas, de ápice redondeado, base decurrente y márgenes crenados a lobulados, con un ángulo de inserción de $60^{\circ}$.

Las pínnulas basales miden $1 \mathrm{~cm}$ de largo y $0,3 \mathrm{~cm}$ de ancho. Poseen márgenes suavemente crenados y venación camptódroma y cladódroma. Vena media derecha y ramificada, extendiéndose hasta el ápice de la lámina, venas secundarias recurvadas y ramificadas, con un ángulo de divergencia agudo. Generalmente, las venas secundarias se ramifican dos veces, salvo las basales, que pueden ramificarse tres y cuatro veces.

Las pínnulas medias presentan sus márgenes crenados y sus venas secundarias recurvadas y dos a tres veces ramificadas.

Las pínnulas apicales miden $0,4 \mathrm{~cm}$ de largo y $0,2 \mathrm{~cm}$ de ancho, sus márgenes son enteros y sus venas secundarias derechas y sin ramificaciones.

La observación con MEB de los restos cuticulares muestra la presencia de orificios circulares a alargados, irregularmente distribuidos, que indicarían la posición de los estomas.

Esporangios aislados y redondeados, con $0,1 \mathrm{~mm}$ de diámetro, aproximadamente, y una base formada por alrededor de 15 células; estos esporangios se hallan a ambos lados de las venas secundarias, sobre la cara abaxial de la pínnula.

Esporas trilete y monolete. Las esporas trilete poseen un contorno ecuatorial triangular a subtriangular, de lados rectos a convexos y ángulos redondeados, de 36 - $42 \mu \mathrm{m}$ de diámetro. Lesura de ramas rectas, con labios de $1 \mu \mathrm{m}$ de espesor, extendiéndose hasta el borde ecuatorial, alcanzando un largo de $18 \mu \mathrm{m}$. Exina delgada de 1,5 $\mu \mathrm{m}$ de espesor. Cara proximal levemente piramidal, lisa a micropunteada. Cara distal convexa, 
ornamentada por microperforaciones de $0,5 \mu \mathrm{m}$ de diámetro, uniformemente distribuidas. Estas esporas pertenecen a la especie Cyathidites sp. A y son semejantes a las halladas en la Formación Baqueró, Estancia Bajo Tigre, Nivel Fosilífero Brachyphyllum (Archangelsky y Villar de Seoane, 1994, pág. 42, lám. 1, fig. 5). Las esporas monoletes también presentan una exina delgada, lisa a microperforada, con una lesura que ocupa los dos tercios del diámetro de la espora.

En los representantes actuales de la familia Dennstaedtiaceae es comun encontrar esporas triletes y monoletes dentro de un mismo esporangio (Tryon y Lugardon, 1991).

El sedimento correspondiente a estas frondes fue tratado químicamente y en él se hallaron asociaciones polínicas con abundantes granos de polen del tipo Classopollis, Balmeiopsis y Ciclusphaera, y diferentes bisacados. En menor cantidad, se encontraron esporas de briófitas y pteridófitas del tipo Cyathidites con exina lisa o micropunteada, Gleicheniidites, Selaginellites y megasporas del tipo Hughesisporites.

\section{Procedencia}

Estancia Bajo Tigre, Nivel Fosilífero Cladophlebis, Formación Baqueró, Provincia de Santa Cruz, Argentina.

\section{Edad}

Cretácico Inferior (Barremiense tardío - Aptiense temprano).

\section{DISCUSIÓN}

El género Cladophlebis fue creado por Brongniart en 1849 para describir frondes filiciformes estériles del Paleozoico y Mesozoico. Principalmente se aplica a frondes filicoides mesozoicas, que no pueden ser asignadas con certeza a una familia natural. Se sabe que algunas de ellas corresponden a la familia de las Osmundáceas (Boureau y Doubinger, 1975) por haber sido halladas en estado fértil o vinculadas a estípites petrificadas.

La bibliografía existente sobre Cyatheaceas fósiles es escasa y fundamentalmente se refiere a descripciones de rizomas, sin frondes asociadas. La única fronde descrita como una Cyatheaceae se encuentra en el trabajo de Berry (1922), quien en su análisis de la flora terciaria de Chile, define una fronde filiciforme con el nombre de Cyathoides thyrsopterioides, semejante al género actual Thyrsopteris perteneciente a la familia Dicksoniaceae. Éste posee esporas trilete con exina finamente rugulada, siendo endémico de las Islas de Juan Fernández, Chile (Heusser, 1971). La comparación de las pinnas descritas por Berry con las nuestras, permitió observar que no existe ninguna semejanza morfológica entre ambas. Por ello, para poder utilizar el género Cyathoides para nuestras frondes, habría que hacer una enmienda sustancial a la diagnosis original, hecho que podría abarcar distintos géneros pertenecientes a más de una familia.

En cuanto a la familia Dennstaedtiaceae, no existe bibliografía alguna sobre representantes fósiles a nivel megascópico. Appert (1973) en su estudio sobre la flora del Jurásico Superior de la montaña Manamana del sudoeste de Madagascar (Africa), describe varias frondes semejantes a la nuestra, pero todas dentro del género Cladophlebis y aunque en ninguno de los casos se encontraron esporas asociadas a las mismas, Appert (op. cit.) las coloca con duda dentro de la familia Dipteridaceae, que en la actualidad está representada por un único género, Dipteris, que posee esporas monolete, de exina lisa a rugulada. La comparación de estas esporas con las halladas en Cladophlebis tripinnata indica que las especies estudiadas por Appert son diferentes.

En Yao et al. (1993) se crea el género Lixotheca para frondes fértiles de Cladophlebis del Pérmico del norte de China, que comparan con el género actual Trichomanes perteneciente a la familia Hymenophyllaceae, pero tampoco en este caso las frondes estudiadas se asemejan morfológicamente a las nuestras.

\section{CONCLUSIONES}

Los ejemplares aquí estudiados corresponden a frondes fértiles y estériles que han permitido su atribución taxonómica, y por lo tanto, exceden la diagnosis que Brongniart diera para el género Cladophlebis.

Si bien el material analizado se encuentra en excelente estado de preservación, la cantidad de tipos hallados (uno de cada familia), no justifica la creación de nuevos géneros; por lo tanto, se decidió continuar utilizando el género Cladophlebis, hasta obtener una cantidad suficiente de ejemplares asociados a estas familias, que posibilite el establecimiento de entidades taxonómicas nuevas.

Si bien las frondes del tipo Cladophlebis son muy frecuentes en la Formación Baqueró, al igual que las esporas del género Cyathidites, ésta sería la primera vez que puede hacerse una determinación taxonómica con los restos megascópicos encontrados. Además, los estudios palinológicos ya realizados (Archangelsky y Villar de Seoane, 1994), permiten determinar con más exactitud que el sotobosque existente en esta Formación durante el Cretácico Inferior, estaba constituido por asociaciones de pteridófitas herbáceas y arborescentes, donde los representantes de las familias Cyatheaceae y Dennstaedtiaceae eran muy abundantes.

\section{AGRADECIMIENTOS}

Agradezco al Dr. S. Archangelsky por sus sugerencias, la lectura crítica del manuscrito y la realización de las fotos de microscopía óptica; al Dr. E. De La Sota por sus comentarios sistemáticos; a la Dra. M. Ponce por facilitarme el acceso al Herbario del Instituto Darwinion; y al Servicio de Microscopía Electrónica de la Facultad de Ciencias Naturales de la Universidad de La Plata por las fotos del MEB. 


\section{BIBLIOGRAFÍA}

Appert, O., 1973. Die Pteridophyten aus dem Oberen Jura des Manamana in Südwest-Madagaskar. Schweizerische Palaontologische Abhandlungen Mémoires Suisses de Paléontologie, 94, 62 pp.

Archangelsky, S., 1963a. A New Mesozoic Flora from Ticó, Santa Cruz Province, Argentina. Bulletin of the British Museum (Natural History) Geology, 2, 45-92.

Archangelsky, S., 1963b. Notas sobre la Flora Fósil de la zona de Ticó, Provincia de Santa Cruz. Ameghiniana, 3 (2), 57-62

Archangelsky, S., 1967. Estudio de la Formación Baqueró. Cretácico Inferior de Santa Cruz, Argentina. Extracto de la Revista del Museo de La Plata (N.S.) Secc. Paleontología, 5, 63-171.

Archangelsky, S. y Gamerro, J.C., 1966a. Estudio palinológico de la Formación Baqueró (Cretácico), provincia de Santa Cruz. II. Ameghiniana, 4 (6), 201209.

Archangelsky, S. y Gamerro, J.C., 1966b. Estudio palinológico de la Formación Baqueró (Cretácico), provincia de Santa Cruz. III. Ameghiniana, 4 (7), 229236.
Archangelsky, S. y Villar de Seoane, L., 1994. Estudios palinológicos de la Formación Baqueró (Cretácico), Provincia de Santa Cruz, Argentina. VI. Ameghiniana, 31 (1), 41-53.

Berry, E.W., 1922. Contributions to the Paleobotany of Peru, Bolivia and Chile. The Johns Hopkins University Studies in Geology, 4, (Ed. E.B. Mathews) 220 pp..

Boureau, E. et Doubinger, J., 1975. Traité de Paléobotanique, 4 (2), $768 \mathrm{pp}$.

Brongniart, A., 1849. Tableau des genres de végétaux fossiles considérés sous le point de vue de leur classification botanique et de leur classification géologique. Dictionnaire Universal de Histoire Natural, 13, 1-127.

Heusser, C.J., 1971. Pollen and spores of Chile. University of Arizona Press, $167 \mathrm{pp}$.

Hickey, L.J., 1974. Clasificación de la arquitectura de las hojas de Dicotiledoneas. Boletín de la Sociedad Argentina de Botánica, 16 (1-2), 1-26.

Tryon, A. and Lugardon, B., 1991. Spores of the Pteridophyta. Springer-Verlag, $648 \mathrm{pp}$.

Yao, Z., Liu, L. and Zhang, S., 1993. Lixotheca. A new generic name for Permian Cladophleboid fern. Acta Palaeontologica Sinica, 32 (5), 525-539. 